\title{
THE DORSAL LONGITUDINAL FASCICULUS IN DIDELPHIS VIRGINIANA
}

\author{
ELIZABETH L. THOMPSON \\ Department of Anatomy, University of Michigan, Ann Arbor \\ TEN PLATES (SIXTEEN FIGURES) \\ INTRODUCTION
}

Few details of the components of the dorsal longitudinal fasciculus - their origin, their termination or their relationships within the path itself - are known for any group of mammals. Certain components have been described by Bodian ('40) and others in the opossum, but our knowledge of the connections of the fasciculus is far from complete although the position of this mammal in the animal scale makes such knowledge highly significant for comparative work. The accumulating evidence on the functions of the regions from which its known fibers take origin adds new interest to this path. It has, for a long time, been regarded by most observers as a part of the hypothalamic discharge system and as concerned, among other functions, with the distribution of certain olfactory impulses, vital to many mammals but relatively unimportant to man.

The following observations reveal relationships which suggest new functional values for the path and give added significance to its role in the physiology and behavior of mammals, including man.

\section{MATERIAL}

The material used consists of ten brain series from the Huber Neurological Collection of the Department of Anatomy of the University of Michigan. Two transversely cut series, 
one sagittal series and one frontal series were stained with toluidin blue; two transversely cut, one sagittal and one frontal series (prepared by Dr. R. E. McCotter) were stained by the Weigert-Pal method; and two of the transversely cut series were prepared by the Ranson ('11) pyridine silver method as modified by Huber and Guild ('13). The series are complete for the brain and upper cervical cord. All of them are from Didelphis virginiana with the exception of one transversely cut toluidin blue series in which the brain of Didelphis aurita was used.

DESCRIPTION AND DISCUSSION OF THE MICROSCOPIAL MATERIAL

Since this report is based on morphological rather than experimental work, any functional evaluation of the tract must necessarily be tentative and be influenced by our knowledge of the activities of the regions from which the fibers of the fasciculus appear to originate or in which they seem to terminate. In the opossum the dorsal longitudinal fasciculus is a rather complex path which furnishes a connecting link between the various brain centers and a final effective pathway.

The longitudinal fibers of the tract, as delimited in this account, lie wholly within the ventral and ventrolateral portions of the central gray. The system should not be confused with the dorsal longitudinal fasciculus as described by von Kölliker (1896) and others, which is the tract termed by most modern observers the posterior or medial longitudinal fasciculus. The latter bundle runs parallel to the tract under consideration but ventral to it and below the central gray. This terminology is in agreement with that used by Castaldi ('23), who was able, however, to separate the fibers into a medial and a lateral group in the guinea pig. Marburg ('31) also stated that the term dorsal longitudinal fasciculus should be limited to those fibers which are either ventral or slightly ventrolateral to the aqueduct and fourth ventricle. The relations of the dorsal longitudinal fasciculus to centers rostral to the pons were early recognized (Schütz, 1891), although 
Ramón Cajal ('11) questioned the evidence presented for its region of origin.

The dorsal tegmental nucleus (figs. $1,5,12$ ) is regarded by most observers as a way station in the course of the ventral central gray path. Analyses of the function of the descending fibers are based upon what this nucleus receives, to what extent it distributes and to what levels its discharge fibers extend. Edinger ('11), Ranson ('32) and Kuntz ('36) referred to a mammillo-tegmental and a pedunculo-tegmental tract as entering the dorsal tegmental nucleus for synapse. None of these authors mentioned a direct relationship of the fasciculus with the habenular system. Kuntz stated that the main discharge path for this nucleus is the dorsal longitudinal fasciculus, "the fibers of which terminate in relation to the efferent nuclei of the trigeminal and facial nerves and probably the general visceral efferent nuclei of the medulla oblongata." Functionally, he believes the path to be concerned with motor and visceral responses to olfactory stimulation. Tilney and Riley ('21) connected the dorsal tegmental nucleus on its receiving side with the interpeduncular nucleus alone and on the discharge side with the nuclei of the cranial nerves; they also suggested; as a possibility, the extension of the tract into the spinal cord. They stated that "it probably represents an ancient motor pathway connected with the olfactory lobe."

Ariëns Kappers, Huber and Crosby ('36) gave a much more complete analysis of the tract and greatly extended its functional possibilities and relations through the observation of more direct and indirect connections with the dorsal tegmental nucleus. As centers discharging to this nucleus they listed the periventricular diencephalic gray, the dorsomedial hypothalamic nucleus, the ventromedial hypothalamic nucleus, and the posterior hypothalamic nucleus, all of which contributed to the pretegmental dorsal longitudinal fasciculus (the diencephalic periventricular system of Gurdjian, '27, and others), the habenular nucleus, connected through an habenulo-tegmental tract, the mammillary bodies, through a mammillo-tegmental path, and the interpenduncular nucleus, by 
a pedunculo-tegmental bundle. Although they did not state that all of these fibers synapse in the dorsal tegmental nucleus, they made no mention of the presence of fibers within the tract which are uninterrupted at this point. They stated, however, that the path continues through the pons and the medulla oblongata with probable discharge into somatic and visceral nuclei of the cranial nerves, and possibly passes on into the spinal cord. Previously Huber and Crosby ('29 a) had observed fibers passing from the tract to the dorsal efferent nucleus of the vagus nerve and assumed that this fiber system in all probability had similar relations with the other nuclei of cranial nerves of somatic and visceral efferent types and that some of the fibers probably continue into the spinal cord. These observers and others have considered the path chiefly efferent in character. Their account of the rostral portions of this tract stresses particularly its relation to the functionally complex hypothalamic region.

Their analysis of the known and probable connections agrees with the observations on the opossum material under consideration. If future experimental work substantiates the morphological data, the tract would seem to play a more important functional role in the life of mammals than has been recognized.

The dorsal longitudinal fasciculus of the opossum is located in the central gray of the mesencephalon, below and slightly lateral to the aqueduct. It originates from a number of different sources in the diencephalon and continues for an undetermined distance caudally, occupying, throughout its course, the same position with respect to the ventricles. The fibers are for the most part non-medullated or lightly medullated. Although the tract is, in the main, an efferent path, there are indications that it also contains ascending components. For convenience in description it is separated into two parts: (a) a portion which lies rostral to the dorsal tegmental nucleus of the mesencephalon and (b) a portion which continues caudalward from this nucleus and which includes components 
arising from the nucleus and those which are added to the fasciculus or diverted from it caudal to this gray.

\section{Rostral division of the dorsal longitudinal fasciculus}

The fibers of the rostral division are derived from a number of sources and have various nuclei of termination. Many of them, primarily the ventral fascicles, enter the dorsal tegmental nucleus. The dorsal components, however, pass above this nucleus, apparently without interruption, and proceed backward with fibers emerging from the cell mass, to become portions of the caudal division of the fasciculus.

Habenular component. Fibers were traced from the ventral surface of the caudal poles of the medial and lateral habenular nuclei ventrocaudally in relatively large numbers. In its relation to the dorsal longitudinal fasciculus the habenular system falls into two portions, both of which enter the fasciculus rostral to the dorsal tegmental nucleus. The fibers forming the dorsal habenulo-tegmental tract (fig. 6) appear to take the more direct route to the dorsal longitudinal fasciculus. They are very lightly medullated, fairly numerous and easily traced in our Weigert-stained sagittal series, and form a fairly broad, compact bundle which leaves the main group of habenular fibers near the level of the ventral border of the posterior commissure. These fibers pass under the ventral surface of the commissure, in company with but beneath the habenulo-tectal and tecto-habenular paths. They again swing dorsally and caudally away from the tectal group into the central gray below the aqueduct. The majority of the fibers of the habenulo-peduncular tract (fig. 8), emerging from the caudoventral borders of the medial and lateral habenular nuclei, continue downward and backward as a robust bundle. This bundle proceeds in an almost direct line to the interpeduncular nucleus, located near the ventral surface of the mesencephalon in its midline. It shows the relationships usual for mammals. A relatively broad, thin band of accompanying fibers from the habenular system, the ventral habenulo- 
tegmental tract (fig. 8), leaves the caudal border of the habenulo-peduncular tract as this latter approaches the rostrolateral surface of the interpeduncular nucleus and curves caudodorsally in an are of about sixty degrees. It joins the rostral fascicles of the pedunculo-tegmental tract, entering. the ventral part of the central gray at the level of the caudal end of the oculomotor nucleus. It is possible that some of the fibers terminate in this nucleus; others, however, appear to continue through the region occupied by the dorsal longitudinal fasciculus dorsal to the oculomotor nucleus and become incorporated in this fasciculus, after which they are indistinguishable from the other components.

The habenular nuclei receive impulses from the olfactory trigone through the olfacto-habenular path (the relations of which have been fully discussed for the opossum by Loo, '31), from the olfactory cortex through the fornix and stria medullaris, and from the amygdaloid nucleus by way of stria terminalis and stria medullaris (Johnston, '23; Gurdjian, '25). Gurdjian ('27), however, believed the latter connection to be slight in the albino rat. As has been seen, the habenular nuclei in the opossum discharge directly or through the dorsal tegmental nucleus into the dorsal longitudinal fasciculus by means of two fiber groups - the dorsal and ventral habenulotegmental components of the dorsal longitudinal fasciculus and indirectly to the motor centers via the interpeduncular nucleus (by the habenulo-peduncular tract) and to the tectal region through the habenulo-tectal system.

Hypothalamic components. The hypothalamic components of the dorsal longitudinal fasciculus are secondarily divisible into those which are related to the tuber cinereum and those which are connected with the mammillary body. Fibers from more rostral parts of the diencephalic region, chiefly from the tuber cinereum - the hypothalamic periventricular gray and the dorsal hypothalamic nucleus-accumulate into fascicles which proceed dorsocaudally close to the lateral and ventro-lateral borders of the ventricle and internal to the central gray. Slightly farther caudalward they are joined by 
a larger bundle of fibers which originates in the dorsomedial and posterior hypothalamic nuclei (fig. 10, A). These latter pass dorsally in rather straight lines until near the central gray and there combine with the more rostral hypothalamic component. The two bundles form the front end of the dorsal longitudinal fasciculus.

Huber and Crosby ('29 a) stated with regard to the diencephalic periventricular system that "it receives visceral impulses from the tuber cinereum region and correlates these with impulses received from somatic centers of the dorsal thalamus and with gustatory." They also mentioned a discharge "to the tectal and tegmental areas of the midbrain, from which centers pathways are open to somatic and visceral efferent centers by way of tecto-spinal paths and the dorsal longitudinal fasciculus of Schütz." Later the entire periventricular complex was analyzed further by Ariëns Kappers, Huber and Crosby ('36), whose account should be consulted for additional functional details and diencephalic relationships.

The mammillary bodies, which receive impulses from the olfactory cortex by way of the fornix, from the medial forebrain bundle (Tsai, '25; Loo, '31; Krieg, '32 ; Gurdjian, '25, '27; and others), from the tuber cinereum and from the mammillary peduncle, discharge in part, in the opossum, through the hypothalamic components of the dorsal longitudinal fasciculus. The mammillary contributions to these components are of two general types. The first type consists of fibers which enter the dorsal longitudinal fasciculus directly and which will be considered here as the mammillary component (fig. 10) of the fasciculus. The second group is made up of fibers which carry impulses to the fasciculus by way of the dorsal tegmental nucleus, such bundles constituting the mammillo-tegmental and ventral mammillo-tegmental tracts of the present account.

The mammillary component (fig. 10) originates in the medial mammillary nucleus. Although lateral and ventral nuclei as described by Tsai ('25) and in greater detail by 
Bodian ('39) were observed in our opossum material, they do not appear to be directly related to the tract under consideration. This component, which emerges as a broad, thin band of lightly medullated fibers from the rostrodorsolateral surface of the mammillary body, lies medial and rostral to the mammillo-thalamic tract, which it parallels during the early part of its course. It sweeps rostrodorsally toward the lower border of the thalamus. As it approaches the ventrolateral surface of the posterior hypothalamic nucleus the tract turns sharply dorsocaudalward, most of its fibers passing over the laterodorsal face of the nucleus. This ribbon-like band twists slightly as it turns and separates into three ill-defined bundles of loosely grouped fascicles. The most ventral of these groups is formed from the most rostral fibers as they leave the mammillary body. At least a part of the fibers of this latter group are apparently interrupted in the posterior hypothalamic nucleus and possibly in other hypothalamic gray. The majority of the remaining fibers appear to join the hypothalamic components of the dorsal longitudinal fasciculus.

The ventral mammillo-tegmental tract (figs. 9 and 10) is composed of fibers emerging from the caudal part of the medial nucleus of the mammillary body. These fascicles curve dorsally and caudally over the dorsal surface of the interpeduncular nucleus. Then they again turn fairly sharply dorsalward, merging with the rostral fibers of the pedunculotegmental path, to join the cephalic segment of the dorsal longitudinal fasciculus in the region of the caudal end of the oculomotor nucleus.

Ramón Cajal ('11) believed that the mammillo-tegmental tract of mammals is formed by a bifurcation of the fibers constituting the mammillo-thalamic tract, and such appears to be the condition existing in most of the forms described. In the albino rat brain, however, Gurdjian ('27) found not only fibers of Cajal's type but also fascicles turning caudalward which were independent and not the products of bifurcation. Although unable to follow such non-dividing fibers to their termination, he suggested that their probable point of synapse 
is the ventral tegmental nucleus. Tsai ('25) traced some fascicles of the mammillo-tegmental tract to the ventral tegmental nucleus and suggested that they might also reach the dorsal reticular region and possibly the central gray of the midbrain. Krieg ('32) was unable to trace the path in his albino rat material and Kuntz ('36) stated definitely that "the mammillo-tegmental tract terminates in the dorsal tegmental nucleus." In the opossum a large tract, chiefly mammillotegmental fibers but accompanied at its origin by a few mammillo-thalamic bundles (hence labelled TR.MAM.THAL., figs. $7,10)$ enters the tegmentum but was not traced to its termination although a few fibers (TR.MAM.TEG., fig. 10) may join the dorsal longitudinal fasciculus.

Bodian ('40) described another connection from the mammillary region to the dorsal tegmental nucleus. This is constituted by a group of fibers, one of three fascicles formed from the mammillary component of the fornix, which he traced from the capsule of the mammillary body through the supramammillary decussation. After crossing, these fascicles turn caudad and their course becomes indistinct. "Fibers of similar appearance but not clearly continuous with" these fascicles were traced to the margin of the interpeduncular nucleus, where they joined the pedunculo-tegmental path en route to the caudal part of the dorsal tegmental nucleus. The fasciculus described by Bodian has not been identified with certainty by the present observer; however, a ventral mammillo-tegmental tract distinct from the mammillo-thalamic system has been found in the available material and will now be briefly described. This tract appears to leave the dorsocaudal border of the mammillary body. As the fibers pass through the mesencephalic tegmentum on their course dorsalward, in company with the pedunculo-tegmental tract, they constitute a small compact group which maintains its integrity and is readily traceable, but which lies in the rostral rather than the caudal part of the pedunculo-tegmental system, as had the tract described by Bodian. Only traces of such a system in the caudal part of the pedunculo-tegmental tract could be demon- 
strated. The ventral mammillo-tegmental fasciculus of this report was not mentioned by Tsai ('25) in his account of the opossum midbrain. In conclusion, it may be said that the discharge of the hypothalamus directly through the dorsal longitudinal fasciculus or indirectly via the dorsal tegmental nucleus is significant in the light of the general interest in this region in mammals.

The relations of the hypothalamic nuclei have been described by Gurdjian ('27) and Krieg ('32) for the albino rat, Rioch ('29) for the cat and dog, Tsai ('25) and Bodian ('39) for the opossum, and Ariëns Kappers, Huber and Crosby (' 36 ; see also Huber and Crosby, '29 a) for various submammalian and mammalian forms. The physiology of the region has been discussed in some detail by Müller ('24) and others. Still more recently the reports of Hinsey ('40), Ingram ('40), Magoun ('40), Ranson ('40), Sheehan ('40), White ('40), Crosby and Woodburne ('40) and others have shown the anatomic pattern and phylogenetic development of the several centers in various forms and covered the current physiological and experimental aspects of the area. Kennedy ('40 a, ' $40 \mathrm{~b}$ ), in discussing the hypothalamus from the clinical point of view, suggested that in addition to the fact that this region is related to many vegetative functions, it also controls the rhythm with which these functions are carried out.

Tectal components. The tectal components of the dorsal longitudinal fasciculus (fig. 11) are formed by fibers which enter the dorsal part of the central gray from both the superior and inferior colliculi. These fibers pass ventrally and caudally along the lateral border of the aqueduct to the region of the dorsal longitudinal fasciculus. Those from the superior colliculus reach the tract in the region of the chief nucleus of the oculomotor nerve and those from the inferior colliculus join it near the level of the nucleus of the trochlear nerve.

The optic tectum has been intensively studied in a number of forms and its relations fully discussed by Huber and Crosby ('26, '29 a, '29 b, '33) and by Ariëns Kappers, Huber and Crosby ('36). It has been recognized by them as an important 
sensory correlation center in many forms. They stated that "in lower mammals the superior colliculi serve for visual and other types of reflexes" and that "the inferior colliculi are auditory reflex centers."

The fibers entering the superior collicular region are numerous and have been enumerated in the references quoted. They comprise not only fibers from the cortex, the striate body, the thalamus and epi- and hypothalamus, including the diencephalic periventricular region, and the cerebellum, but also ascending sensory systems and those carrying visual and, indirectly, auditory impulses. The centrifugal fibers of this region are also far reaching. Of particular interest are the descending paths of the tecto-bulbar and tecto-spinal series, the fibers of which terminate on motor neurons and on the cell bodies of preganglionic fibers completing motor and visceral reflex arcs. The addition of tectal fibers to the dorsal longitudinal fasciculus, which is also in relation with somatic and visceral centers of the brain stem and probably, to some extent at least, of the spinal cord, appears to give to this system the role of an accessory descending tectal path.

Components from the gray of the posterior commissure and medial longitudinal fasciculus. The ventral nucleus of the posterior commissure (figs. 4, 5) is located ventral to the dorsolateral curve of this commissure at the lateral border of the central gray, and dorsolateral to the aqueduct as this opens out of the third ventricle. The nucleus projects slightly into the central gray but the greater part of the cell mass is located in relation with the fibers of the commissure. From the ventromedial surface of the ventral nucleus, lightly medullated fibers fan out toward the midline. Some of these pass above the aqueduct. The greater portion of the fibers tilt ventrally and caudally into the central gray below the aqueduct where they appear to join the caudally directed fascicles of this area, dorsal to the rostral portion of the oculomotor nucleus.

The nucleus of the medial longitudinal fasciculus (fig. 5) lies along the lateral border of the central gray near the ventromedial edge of the ventral nucleus of the posterior 
commissure (with the cells of which it appears to mingle) and extends to the level of the rostral end of the motor part of the oculomotor nucleus. Its ventral border is marked by a larger, rounded column of cells resting in the ventrolateral angle of the central gray, the lateral cells of which appear among the fibers of the medial longitudinal fasciculus. From the inner surface of this nucleus, particularly from its ventral portion, fascicles swing medially between the aqueduct and the oculomotor nerve into the region of the dorsal longitudinal fasciculus. The addition of fibers from the ventral nucleus of the posterior commissure and the interstitial nucleus of the medial longitudinal fasciculus to the dorsal longitudinal fasciculus gives to this latter bundle the same conditioning functions attributed to the comparable components in the medial longitudinal fasciculus. The fibers received by these two nuclei are not well known and little is to be found in the literature regarding their relations in the opossum. In certain other forms (considered in the references already quoted) these nuclei are thought to receive fascicles from the cortex and also from the striate region by way of ansa lenticularis, and, in addition, fascicles from the ascending components of the medial longitudinal fasciculus.

Components associated with the rostral eye-muscle nuclei. The chief oculomotor nucleus (figs. 1, 10, 12) forms a column of cells on either side of the midline at the ventral border of the central gray. In horizontal toluidin blue sections, each - mass appears somewhat crescent shaped. The points of the crescent are blunt and the convex surface is directed toward the midline but does not appear to touch it. In the midline between the diverging cephalic ends of these cell masses, and projecting for about half of its length rostral to them, lies the Edinger-Westphal nucleus. The dorsal longitudinal fasciculus, as it passes caudalward in its course, is located between these nuclear masses and the aqueduct. Fibers were traced from the fasciculus into both the somatic and visceral portions of the oculomotor nuclei (figs. 4, 10, 12). Whether they represent 
afferent or efferent components, or both, with respect to these nuclei, could not be determined from the material.

In the opossum the trochlear nucleus is a small, rounded, compact mass of large neurons located caudal (fig. 1) to the oculomotor nucleus. In frontal toluidin blue sections the oculomotor and trochlear nuclei of both right and left sides appear continuous with each other. The caudal and caudomedial borders of the trochlear nucleus are adjacent to the smaller, paler staining cells of the dorsal nucleus of the raphé, but the two cell masses are sharply delimited by differences in cell character. Most of the fibers from the dorsal longitudinal fasciculus pass above the trochlear nucleus, but a few of them diverge from the tract to turn ventrally into the nucleus. Again the direction of conduction is unknown.

Interpeduncular component. The interpeduncular nucleus (figs. 8, 9, 10) is located in the midventral part of the mesencephalic tegmentum and extends from near the point of emergence of the fibers of the oculomotor nerve to the region of the first pontine fascicles. The cell bodies of the central portion of the nucleus are larger and more closely grouped than the superficial cells. They give origin to axons, many from the more ventral areas of the nucleus, which sweep dorsalward within the nuclear gray in several definite bands. After leaving the nucleus these fibers (figs. 10,12) continue dorsally through the middle of the tegmentum in straight lines, diverging slightly as they proceed, so that they enter the central gray over a considerable rostrocaudal area. Some of them reach this gray rostral to the trochlear nucleus; the majority, however, enter the dorsal tegmental nucleus (fig. 12), and a few penetrate the central gray caudal to it. Many of the more rostral fibers appear to join the dorsal longitudinal fasciculus directly but those of the middle portion enter the dorsal tegmental nucleus.

In conclusion it may be said that the interpeduncular nucleus receives fibers from the epithalamus by way of the habenulo-peduncular path and from the hypothalamus through the mammillo-peduncular path. Tsai ('25) added to these an 
olfacto-peduncular path which he believed to be a part of the medial forebrain bundle in the opossum. The first two groups of fibers carry somato-olfactory and visceral-olfactory impulses and probably put this nucleus in relation with other hypothalamic visceral centers as well. Most reports agree that at least a part of the fibers emerging from the interpeduncular nucleus terminate in the dorsal tegmental nucleus and adjacent gray. Our observations are in agreement with those of Kuntz ('36), who stated that a part of the pedunculotegmental tract appears to enter the nucleus incertus just caudal to the dorsal tegmental nucleus.

\section{Caudal division of the dorsal longitudinal fasciculus}

The caudal division of the fasciculus is that portion which begins rostrally at the dorsal tegmental nucleus and continues caudally into upper spinal cord levels. In horizontal Weigert sections its fibers can be traced into the ventral funicular region of the upper cervical cord (fig. 16). Here they lie beneath the anterior white commissure and become masked by endogenous fibers of the region. In part this caudal division is a direct continuation of the rostral portion, the separation between them being merely arbitrary and made for purposes of description. Like the rostral portion it is formed by various components of diverse origin and termination.

Dorsal tegmental nuclear component. The dorsal tegmental nucleus (figs. 1, 5,12), which marks the beginning of this caudal division of the dorsal longitudinal fasciculus, is located within the central gray below the aqueduct, dorsal and then caudal to the nucleus of the trochlear nerve, and approaches the nucleus incertus caudally. It is a group of medium and small sized cells, the rostral limits of which are ill defined so that other gray in the region has been grouped with it by some observers (Castaldi, '23; Tsai, '25).

Castaldi ('23, '24) mentioned a nucleus of the ventral central gray in the guinea pig which overrides the dorsal tegmental nucleus and projects rostral to it to a point between the diverging caudal poles of the trochlear nucleus and which at its 
caudal end approaches nucleus incertus. The dorsal tegmental nucleus and the dorsal nucleus of the raphe are so closely merged that it is impossible to differentiate them completely in our material except on the basis of cell character. The neurons of the dorsal tegmental nucleus are small and medium sized, with the small cells deeply stained in the toluidin blue material, and those of the nucleus of the dorsal raphé are smaller and are less deeply stained. Tsai ('25) figured the dorsal tegmental nucleus dorsal to the caudal end of the oculomotor nucleus in the opossum. The dorsal tegmental nucleus is almost fused with its fellow of the opposite side in the midline but shows a thinning of cells which suggests its essentially paired character.

The dorsal tegmental nucleus is located practically within the course of the dorsal longitudinal fasciculus and it appears to receive fibers from the rostral segment of the tract as well as from the interpeduncular nucleus through its outlet, the pedunculo-tegmental tract (fig. 12). Fibers emerge from the dorsal and caudal surfaces of the dorsal tegmental nucleus to join those fascicles of the dorsal longitudinal fasciculus which, having accumulated rostral to this nucleus, pass above it without interruption (fig. 12).

It is impossible to state from observation whether or not all of the fibers passing through this nucleus are interrupted in course, but that portion of the descending path caudal to the nucleus has quite generally been regarded as originating within it. Those fibers passing dorsal to the nucleus may arise in part from more rostral centers and, in part at least, may be ascending fibers.

Nucleus incertus component. Nucleus incertus (fig. 12) lies in the isthmus region directly caudal to the dorsal tegmental nucleus. In the material studied, its cells, which are predominantly medium sized, are more closely grouped and somewhat more deeply stained than those of the former nucleus. It also appears to interrupt the fibers of the ventral portion of the dorsal longitudinal fasciculus, from which it receives (see fig. 12, $X$ ) and into which it sends fascicles. Nucleus 
incertus also receives a few fibers of the caudal portion of the pedunculo-tegmental tract as these enter the central gray caudal to the dorsal tegmental nucleus.

The nucleus incertus itself either is not apparent or has been disregarded in most descriptions of the region. Streeter ('03) located it in the adult human brain in the floor of the fourth ventricle, dorsal to and closely related to the nucleus of the trigeminal nerve and extending into the region of the midbrain. He stated that "its function is unknown". Castaldi ('23) identified this nuclear mass in the guinea pig and figured fiber connections between it and the dorsal tegmental nucleus. It seems probable that nucleus incertus is to some extent functionally comparable to the dorsal tegmental nucleus in that it receives fibers of the same type and discharges at least a part of its fascicles into the same path. Whether or not it has other functional relations is a matter for further study.

Components related to certain pontine and medullar nuclei. The connections of the caudal division of the dorsal longitudinal fasciculus with the cranial nerve centers along its course may well be considered together.

Motor trigeminal component. In the opossum the motor nucleus of the trigeminal nerve (fig. 2 ) is located in the lateral tegmental field of the pons, medial to the trigeminal root. Fibers leave the dorsal longitudinal fasciculus in the region of nucleus incertus to pass ventralward over the medial border of this nucleus, and then laterally and ventrally under and through its ventral border, where they appear to be joined by a few fascicles from the nucleus itself. A few fibers leave the fasciculus dorsal to nucleus incertus, curve ventrally and laterally over its lateral border, and then join the former group. The combined bundle passes laterally and ventrally to the motor nucleus of the trigeminal nerve. In the Weigert sagittal series certain fibers were followed ventralward and lateralward from the dorsal longitudinal fasciculus to a position caudal to nucleus incertus and rostral to the genu of the facial nerve, being somewhat closer to the former. As they leave the fasciculus they curve away from it in a rostral direc- 
tion at an angle which suggests that they are ascending in the system. These fibers join the other bundles passing to the motor nucleus of the trigeminal nerve.

Abducens component. The chief nucleus abducens (fig. 2) in the opossum, as in other mammals, is located directly under the genu of the facial nerve, which in this marsupial is a relatively large root jutting up into the central gray and forming a prominent facial colliculus. The dorsal longitudinal fasciculus lies as an irregularly elongated crescent over its medial, dorsal and dorsolateral surfaces.

Certain bundles leave the fasciculus to swing around the lateral surface of the facial root into the abducens nucleus. A few fibers follow the medial surface of the facial colliculus to enter this nucleus, and, in sagittal sections, other fascicles can be observed to cut through the genu from its dorsal surface and to enter the nucleus. Sagittal Weigert sections in planes through the lateral border of the facial colliculus show still other fascicles, possibly of ascending type, curving. rostrally and ventrally into the abducens nucleus.

Components related to efferent facial gray. These components are of two types, for both the general and the special visceral efferent centers of the facial nerve have connections with the dorsal longitudinal fasciculus.

The superior salivatory nucleus (figs. 2, 3), a general visceral efferent center for the facial nerve, is located lateral, ventral and caudal to the facial colliculus and not far from its ventrocaudal border. Two types of fibers, differentiated on the basis of their angle of approach, associate it with the dorsal longitudinal fasciculus. Certain fibers curve caudolaterally over the dorsal surface of the colliculus to join fascicles from near its lateral surface, the bundles then proceeding in a ventrolateral direction to the superior salivatory nucleus. In sagittal Weigert sections other fibers were followed from the dorsal longitudinal fasciculus to the superior salivatory nucleus, entering at an angle which suggests that they may be afferent with respect to the nucleus. 
The motor nucleus of the facial nerve (fig. 2) is located in the lower ventrolateral field, lateral, ventral and caudal to the motor trigeminal nucleus and rostral to nucleus ambiguus, with which it is nearly in a rostrocaudal line. Certain fibers from that portion of the dorsal longitudinal fasciculus which is medial to the facial colliculus and others from its lateral side pass ventralward and slightly lateralward toward the facial nucleus. Sagittal Weigert sections show still other fibers leaving the dorsal longitudinal fasciculus slightly caudal to those just described and in a rostrally directed arc. They curve around the medial and ventral surfaces of the facial colliculus and then pass laterally and ventrally toward the motor nucleus of the facial nerve. These latter leave the dorsal longitudinal fasciculus at an angle which suggests that they are afferent to the nucleus.

Components related to efferent glossopharyngeal and vagal gray. The general visceral efferent center of the glossopharyngeal nerve, the inferior salivatory nucleus (figs. 2, 3), is not sharply separated from the dorsal efferent nucleus of the vagus nerve. The entire nuclear group lies near the ventral border of the central gray, lateral to the nucleus of the hypoglossal nerve, which forms a long column of cells on either side of the midline. In both transverse and sagittal sections, fibers from the dorsal longitudinal fasciculus are traceable lateralward and slightly ventralward into this nucleus.

The dorsal efferent nucleus of the vagus nerve (figs. 2,3 ) is comparatively large and occupies the same relative position as does the inferior salivatory nucleus but is caudal to it. In sagittal sections (fig. 13) rather large numbers of very delicate fibers turn into this nucleus from the dorsal longitudinal fasciculus at an angle which suggests that they are ascending fibers with reference to the nucleus. They appear to enter the nucleus throughout its entire extent.

Fibers also course from the dorsal longitudinal fasciculus to nucleus ambiguus (fig. 13). In the opossum this nucleus is located in the ventrolateral field of the medulla oblongata in about the same relative position as that occupied by the motor 
nucleus of the facial nerve as the two were observed in sagittal toluidin blue sections. The cells of nucleus ambiguus are fewer and less compactly arranged than those of the facial nucleus. In Weigert preparations lightly medullated fibers leave the dorsal longitudinal fasciculus, pass medially and ventrally over the medial surface of the hypolossal nucleus and then course ventrolaterally in the direction of nucleus ambiguus. Others turning off the fasciculus run laterally and ventrally between the hypoglossal nucleus and nucleus intercalatus which lies immediately lateral to it (fig. 14). These fibers continue laterally and ventrally toward the region of nucleus ambiguus. It is not possible in our material to trace either group into the nucleus. The above fibers pass near if not through the medial reticular nuclear area of the medulla oblongata (fig. 15) and it is possible that some of them synapse there.

Hypoglossal component. The hypoglossal nucleus (figs. 2, 3, $14,15,16)$, located ventral to the dorsal longitudinal fasciculus and lateral to its medial portion, extends nearly through the medulla oblongata and receives fibers from the fasciculus throughout its length.

Component related to the gray of fasciculus solitarius. This gray of the solitary fasciculus (figs. 3,14 ) partially surrounds and lies partly within the fasciculus and is situated lateral and slightly dorsal to the dorsal efferent nucleus. Fibers emerging from it pass dorsally and medially over the medial surface of the dorsal efferent nucleus and also dorsally over its lateral surface. Both groups enter the central gray to mingle with the fibers of the dorsal longitudinal fasciculus.

The gray associated with the solitary fasciculus has long been recognized as nuclei of reception for general visceral and special visceral afferent components of the facial, glossopharyngeal and vagus nerves. The course of the secondary ascending fibers has been in doubt. $\mathrm{By}$ experimental procedures Allen ('23 a, '23 b)' studied both the distribution of entering visceral sensory fibers of these nerves to brain stem areas and their projection from such centers to the dien- 
cephalon. He stated that "None of the sensory fibers of the VIIth, IXth or Xth (having cell bodies in the ganglion nodosum) nerves are distributed anywhere but to the tractus solitarius." He believed that the impulses are carried to the dorsal thalamus from the gray of fasciculus solitarius by way of the medial lemniscus. The present study suggests that an ascending path to the hypothalamus may be provided through the dorsal longitudinal fasciculus. It must be remembered that Wallenberg (1899) carried ascending impulses to the hypothalamic region through the mammillary peduncle.

Component related to nucleus intercalatus. Fibers from nucleus intercalatus (fig. 14) pass into the dorsal longitudinal fasciculus. This nucleus occupies a part of the relatively narrow space between the dorsal efferent nucleus and the hypoglossal nucleus. For the most part nucleus intercalatus lies slightly dorsal as well as medial to the dorsal efferent nucleus. Toluidin blue and silver sections show that it contains relatively small fusiform and angular cells. In transverse sections stained by the pyridine silver method, some neuraxes of these cells can be traced into the hypoglossal nucleus and others, in considerable number, enter the dorsal longitudinal fasciculus. Root fibers of the glossopharyngeal and vagus nerves (Ariëns Kappers, '20; DuBois, '29) have been traced to nucleus intercalatus.

Opinions have differed as to the functional significance of nucleus intercalatus of Staderini. Streeter ('03), Stokes ('12), DuBois ('29) and Voris and Hoerr ('32) believed it to be either wholly or in part indistinguishable from the medial vestibular nucleus. Ariëns Kappers ('20; see also his account in Ariëns Kappers, Huber and Crosby, '36) regarded this nucleus as related to the gustatory path. He thought it received taste fibers by way of the facial, glossopharyngeal and vagus nerves and relayed these impulses, at least in part, to the nucleus of the hypoglossal nerve to complete the gustatorytongue reflex.

Marburg' ('31) and his co-workers, who regarded the dorsal longitudinal fasciculus as containing ascending as well as 
descending fibers, traced fascicles to it from the gray of the solitary fasciculus and from the caudal end of nucleus intercalatus. They gave little information on the function of these fibers other than to suggest that the intercalate nucleus may be related to the vestibular group of nuclei as well as to receptive gray of the facial, glossopharyngeal and vagus nerves. It seems probable that they refer to the rostral portion of nucleus intercalatus in the suggested vestibular relationship.

Barnard ('36) found fibers from the solitary fasciculus passing into the region of the intercalate nucleus in the mouse. $\mathrm{He}$ stated that "the evidence for the mouse indicates that Staderini's nucleus is not associated particularly with the gustatory system." According to this author, however, nucleus intercalatus is indistinct in the mouse.

None of these observers except Marburg has suggested the dorsal longitudinal fasciculus as a secondary path for ascending fibers for this region. The material available for study documents Marburg's contention that the dorsal longitudinal fasciculus carries ascending as well as descending fibers and indicates that it provides an outlet for impulses from nucleus intercalatus by which they may reach various efferent centers of the brain stem and possibly other higher brain levels.

It is recognized that the dorsal longitudinal fasciculus is not the only discharge path for the various nuclei concerned. However, the diversity of its components makes it an important path in the interpretation of somatic and visceral reflexes in mammals. Experimental work is definitely needed to clarify and check these observations.

Spinal component. The dorsal longitudinal fasciculus passes at the lower end of the medulla oblongata into the ventral funiculus of the spinal cord (fig. 16), where it becomes a part of the ventral proprius bundle. The available series include only the upper cervical segments, so that the caudal extent of the fasciculus could not be determined. This extension into the cord has been rather generally recognized by students of the system. 
The dorsal longitudinal fasciculus is related to epithalamic and hypothalamic regions of the diencephalon, to the tectal areas and the base of the midbrain, to the preganglionic and motor centers of the cranial nerves and to the efferent centers of the cervical cord, to various afferent cranial centers, most specifically the gray of fasciculus solitarius and nucleus incertus, and to certain masses of gray along its course, the most prominent of which is the dorsal tegmental nucleus. It is obvious that it is a composite of ascending and descending fibers, with the latter predominating. Its connections suggest that it coordinates the activities of cranial nerve nuclei.

The dorsal longitudinal fasciculus is continued beyond the medulla oblongata into the spinal cord. The components included in the fasciculus give it an important functional significance in reflexes involving olfactory, gustatory, visceral and somatic centers of the brain stem and probably of the spinal cord. A conditioning cortical element is present. There is probably a supplementary or auxiliary relation to the descending tectal paths and a comparable relation to certain elements of the medial longitudinal fasciculus.

As far as could be determined in the material available, all of the relations reported in the literature for this tract in other mammals are present in the nervous system of the opossum. Certain components of the path believed to be hitherto unreported for the opossum have been considered. However, it is recognized that the fiber relations of the dorsal longitudinal fasciculus as described here have only observational significance and that they should be substantiated through experimental work.

\section{LITERATURE CITED}

AlLen, William F. 1923 a Origin and distribution of the tractus solitarius in the guinea pig. J. Comp. Neur., vol. 35, pp. 171-204.

$1923 \mathrm{~b}$ Origin and destination of the secondary visceral fibers in the guinea-pig. J. Comp. Neur., vol. 35, pp. 275-311.

Arïns Kappers, C. U. 1920 Vergleichende Anatomie des Nervensystems. E. F. Bohn, Haarlem. 
Ariëns Kappers, C. U., G. Carl Huber, and E. C. Crosby 1936 The comparative anatomy of the nervous system of vertebrates ineluding man. The Macmillan Company, New York.

Baranad, John W. 1936 A phylogenetic study of the visceral afferent areas associated with the facial, glossopharyngeal, and vagus nerves, and their fiber connections. The efferent facial nucleus. J. Comp. Neur., vol. 65, pp. 503-602.

Bodian, David 1939 Studies on the diencephalon of the Virginia opossum. I. The nuclear pattern in the adult. J. Comp. Neur., vol. 71, pp. 259-323.

1940 Studies on the diencephalon of the Virginia opossum. II. The fiber connections in normal and experimental material. J. Comp. Neur., vol. 72, pp. 207-297.

Cajal, S. RAMón 1911 Histologie du système nerveux. T. 2. Paris.

CASTALdi, L. 1923 Studi sulla struttura e sullo sviluppo del mesencefalo. Ricerche in Cavia cobaya. Parte prima. Arch. ital. di anat. e di embriol:, vol. 20, pp. 23-225.

1924 Studi sulla struttura e sullo sviluppo del mesencefalo. Ricerche in Cavia cobaya. Parte seconda. Arch. ital. di anat. e di embriol., vol. 21, pp. 172-263.

Crosby, E. C., AND R. T. WoodBurne 1940 The comparative anatomy of the preoptic area and the hypothalamus. Res. Publ. Ass. nerv. ment. Dis., vol. 20 , pp. $52-169$.

Du Bors, F. S. 1929 The tractus solitarius and attendant nuclei in the Virginian opossum (Didelphis virginiana). J. Comp. Neur., vol. 47, pp. 189-224.

Edinger, L. 1911 Vorlesungen über den Bau der nervösen Centralorgane des Mensehen und der Thiere. F. C. W. Vogel, Leipzig.

Gurdian, Elisha Stephens 1925 Olfactory conneetions in the albino rat, with special reference to the stria medullaris and anterior commissure. J. Comp. Neur., vol. 38, pp. 127-163.

1927 The diencephalon of the albino rat. Studies on the brain of the rat. No. 2. J. Comp. Neur., vol. 43, pp. 1-114.

Hinsery, J. C. 1940 The hypothalamus and somatic responses. Res. Publ. Ass. nerv. ment. Dis., vol. 20 , pp. 657-685.

Huber, G. Carl, and E. C. Crosby 1926 On thalamic and tectal nuclei and fiber paths in the brain of the American alligator. J. Comp. Neur., vol. 40 , pp. 97-227.

- $1929 \mathrm{a}$ The nuclei and fiber paths of the avian diencephalon, with consideration of telencephalic and certain mesencephalie centers and connections. J. Comp. Neur., vol. 48, pp. 1-225.

$1929 \mathrm{~b}$ Somatie and visceral connections of the diencephalon, Areh. Neur. and Psychiat., vol. 22, pp. 187-229.

1933 A phylogenetic consideration of the optic tectum. Proc. Nat. Acad. Sci., vol. 19, pp. 15-22.

Huber, G. Cart, AND Stacy R. Guild 1913 Observations on the peripheral distribution of the nervus terminalis in Mammalia. Anat. Rec., vol. 7, pp. 253-272.

INGRAM, W. R. 1940 Nuclear organization and chief connections of the primate hypothalamus. Res. Publ. Ass. nerv. ment. Dis., vol. 20, pp. 195-244. 
Jonnstox, J. B. 1923 Further contributions to the study of the erolution of the forebrain J. Comp. Neur., vol. 35, pp. 337-481.

KENNEDY, Foster 1940 a Medical syndromes of the hypothalamus. Res. Publ. Ass. nerv. ment. Dis., vol. 20, pp. 864-874.

$1940 \mathrm{~b}$ The hypothalamus. Jour. A. M. A., vol, 114, pp. 2092-2095.

voN KöLIIKER, A. 1896 Handbuch der Gewebelehre des Menschen. 6. Aufl., Bd. 2. Engelmann, Leipzig.

KrIEG, W. J. S. 1932 The hypothalamus of the albino rat. J. Comp. Neur., vol. 55 , pp. 19-89.

Kuntz, Albert 1936 A text-book of neuro-anatomy. Lea and Febiger, Philadelphia.

Loo, YÜ TAO 1931 The forebrain of the opossum, Didelphis virginiana. II. Histology. J. Comp. Neur., vol. 52, pp. 1-148.

Mugove, H. W. 1940 Descending connections from the hypothalanus, Res. Publ. Ass. nerv. ment. Dis., vol. 20, pp. 270-285.

MaRbure, OTTo 1931 Das dorsal Längsbündel von Schütz-Fasciculus periependymalis - und seine Beziehungen zu den Kernen des zentralen Höhlengrau. Arb. a. d. neur. Inst. a. d. Wien. Univ., Bd. 33, S. 135-164.

MËLleR, L. R. 1924 Die Lebensnerven: ihr Aufbau, ihre Leistungen, ihre Erkrankungen. Julius Springer, Berlin.

Ransox, S. W. 1911 Non-medullated nerve-fibers in the spinal nerves. Am. J. Anat., vol. 12 , pp. 67-87.

1932. The anatomy of the nervous system. 4th ed. W. B. Saunders Company, Philadelphia.

1940 Regulation of body temperature. Res. Publ. Ass. nerv. ment. Dis., vol. 20, pp. 342-399.

Rroch, David McKenzie 1929 Studies on the diencephalon of Carnivora. I. The nuclear configuration of the thalamus, epithalamus, and hypothalamus of the dog and eat. J. Comp. Neur., vol. 49, pp. 1-119.

Schüтz, H. 1891 Anatomische Untersuchungen über den Faserverlauf im zentralen Höhlengrau und den Nervenfaserschund in demselben bei der progressiven Paralyse der Irren. Arch. f. Psychiat., Bd. 22, S. $526-582$.

ShEefian, DoNAL 1940 The hypothalamus and gastro-intestinal regulation. Res. Publ. Ass. nérv. ment. Dis., vol. 20, pp. 589-616.

Strokes, J. H. 1912 The acoustic complex and its relations in the brain of the opossum (Didelphys virginiana). Am. J. Anat., vol. 12, pp. 401-445.

Streeter, G. L. 1903 Anatomy of the floor of the fourth ventricle. Am. J. Anat., vol. 2, pp. 299-313.

Tilney, F., AND H. A. Riley 1921 The form and functions of the central nervous system. P. Hoeber, New York.

TSaI, Chiao 1925 The descending traets of the thalamus and midbrain of the opossum, Didelphis virginiana. J. Comp. Neur., vol. 39, pp. 217-24.8.

VoRis, H. C., AND N. L. HoERr 1932 The hindbrain of the opossum, Didelphis virginiana. J. Comp. Neur., rol. 54, pp. 277-355.

Wallenbera, A. 1899 Notiz über einen Schleifenursprung des Pedunculus corporis mamillaris beim Kaninchen. Anat. Anz., Bd. 16, S. 156-158

WHITE, J. C. 1940 Autonomic discharge from stimulation of the hypothalamus in man. Res. Publ. Ass. nerv. ment. Dis., vol. 20, pp. 854-863. 


\section{PLATES}

\section{ABBREVIATIONS}

A., hypothalamie contributions to dorsal longitudinal fasciculus

crebel., cerebellum

col, inf., inferior colliculus

eol. sup., superior collieulus

com. post., posterior commissure

corp. mam., manmillary body

dien., diencephalon

F., fornix

f.l.d., dorsal longitudinal faseiculus

f.l.m., medial longitudinal faseiculus

f. sol., solitary fasciculus

genu III, genu of the facial nerve

gr. cent., central gray

mam. comp. f.l. d., mannillary com-

ponent of dorsal longitudinal fas. cieulus

med. ret. gl', medial reticular gray

N. III, oculomotor nerve

$\mathrm{X} . \mathrm{X}$, vagus nerve

X. XI, bulbar aceessory nerve

N. XII, lypoglossal nerve

n. I.II, oculomotor nucleus

n. IV, motor nucleus of trochlear nerve

n. V, motor muckes of trigeminal nerve

II. VI, motor nucleus of abducens nerve

n. VII, motor nucleus of facial nerve

11. XII, hypoglossal nucleus

11. amb., ambiguus nueleus

n. dors. com. post., dorsal nucleus of posterior commissure

n. Rors. raphe. dorsal nucleus of raphé

11. Ed. W., Edinger-Westphal nucleus

ı. ef. dors., dorsal efferent mucleus n. f. sol., muclear gray of solitary faseiculus

n. inc., nucleus incertus

u. intercal., interealate nueleus

n. interped., interpeduncular nueleus

n. interst. f. l. m., interstitial nucleus of medial longitudinal fasciculus

il. sal. inf., inferior salivatory nueleus

1l. sal. sup., superior salivatory nucleus

n. tog. dors, dorsal tegmental nueleus

11. vont. com. post., ventral nucleus of posterior commissure

ped. mam., mammillary peduncle

tec., tectum

teg., tegmentum

tr. hab. ped., babenulo-peduneular tract

tr. hab. tec., habenulo-tectal tract

tr. hab. teg. dors., dorsal habenulo-tegmental tract

tr. luab. teg. vent., ventral habemulo-tegmental tract

tr. mam. ped., mammillo-peduneular tract

tr. mam. teg., nammillo-tegmental traet tr. mam. teg. vent., ventral mammillotegmental tract

tr. mam. thal., mammillo-thalamic and mammillo-tegmental tract

tr. ped.teg., pedunculo-tegmental tract

tr.tec. teg., tecto-tegmental tract

$\mathrm{V}$, ventricle

$\mathrm{X}$, indicates position in dorsal longitudinal fasciculus of a possible ascending component 
PLATE 1

EXPLANATION OF FIGURES

1 Photomicrograph of a horizontal section through the eye-muscle nuclei of Didelphis virginiana, illustrating the relations of these cell masses to each other and to the differentiated periventricular nuelei in the midline. Toluidin blue. preparation. $\times 200$.

A'. Key photomicrograph indieating the region shown in figure $1 . \times 1$.

2 Plotomicrograph of a section from the same series as that used in figure 1. but farther ventralward. The relations of the major efferent nuclei of pons and medula oblongata are illustrated. $\times 11$.

B'. Key pliotomicrograph for figure 2. $\times 1 \frac{1}{2}$. 


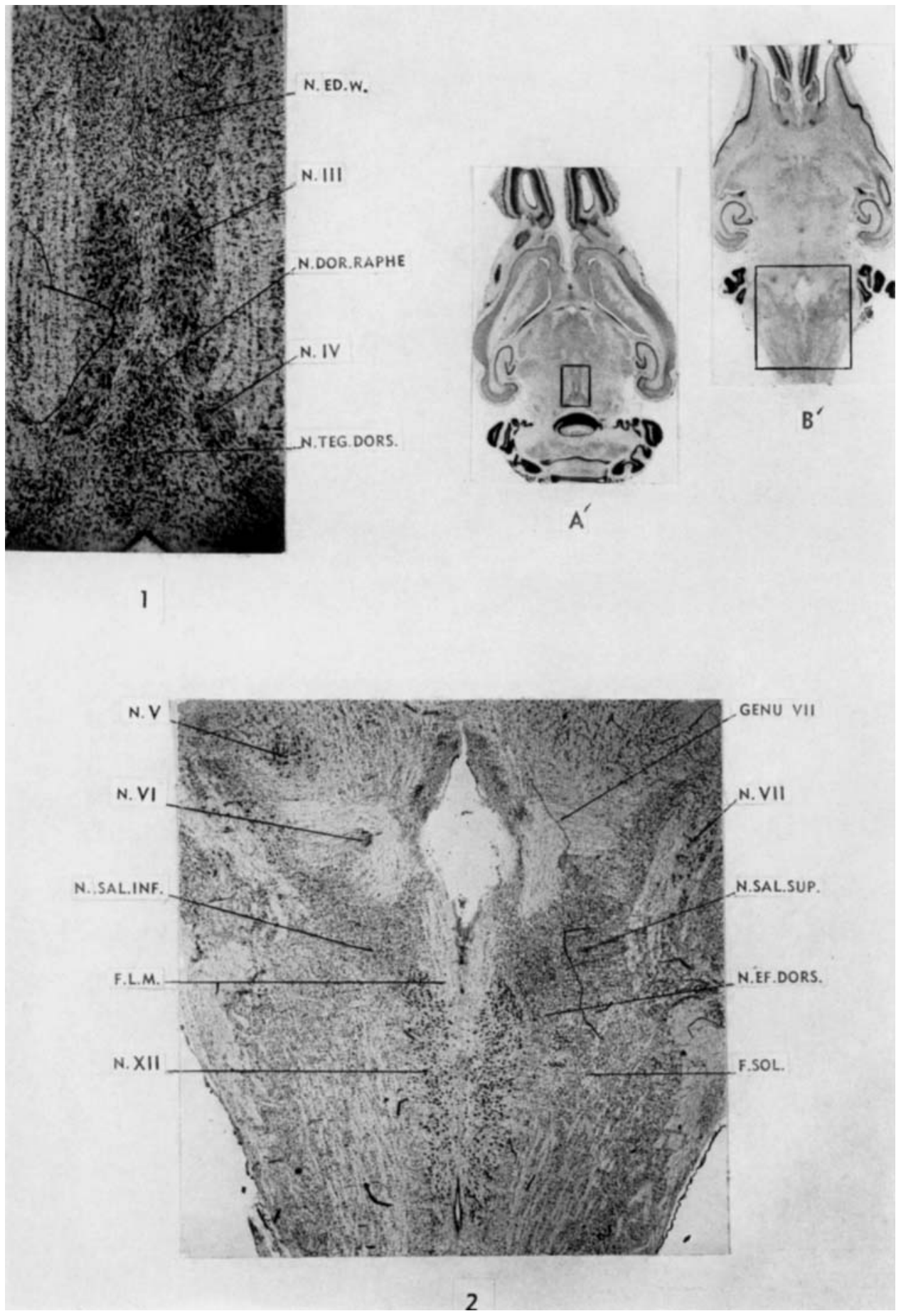


PLATE 2

\section{EXPLANATION OF FIGLRFS}

3 Photomicrograph of a section from the same series illustrated in figure a but approximately $50 \mu$ dorsul to it and at a manification of $20 \times$. The picture illustrates, in somewlat greater detail than does the preceding photomicrograph, the relations of the general visceral efferent column to the hypoghossal nucleus. Toluidin blue preparation.

$A^{\prime}$. Key photomicrograph for figure $3 . \times 1 \frac{1}{2}$.

4 Plotomierograph of a transverse section through the wesencephalon of Didelphis virginiana at the level of the Edinger-Westphal nucleus and the ventral nucleus of the posterior commissure. The position of the dorsal longitudinal fasciculus is indicated. Weigert section. $\times 20$.

I'. Key photomicrograph for figure $4 . \times 3$. 


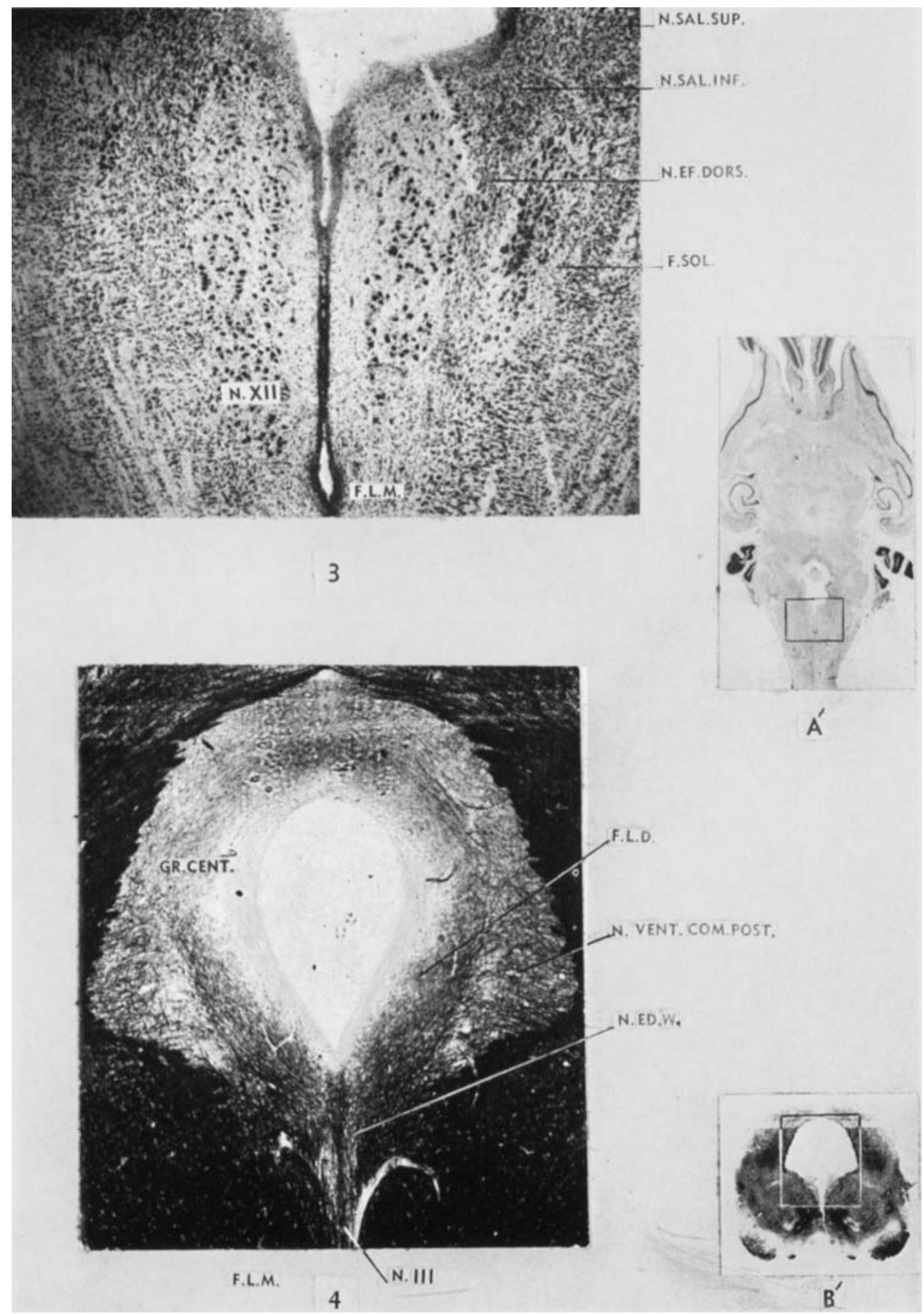


PLATE 3

\section{EXPLANATION OF FIGLRES}

5 Plotomicrograph of a horizontal section from the same series as that used for figure 1, but from a plane approximately $125 \mu$ dorsal to that of the latter. The figure indicates particularly the nuclei of the posterior commissure and the interstitial nueleus of the medial longitudinal fasciculus. Toluidin blue preparation. $\times 20$.

A'. Koy photomicrograph for figure $5 . \times 1$ !. 


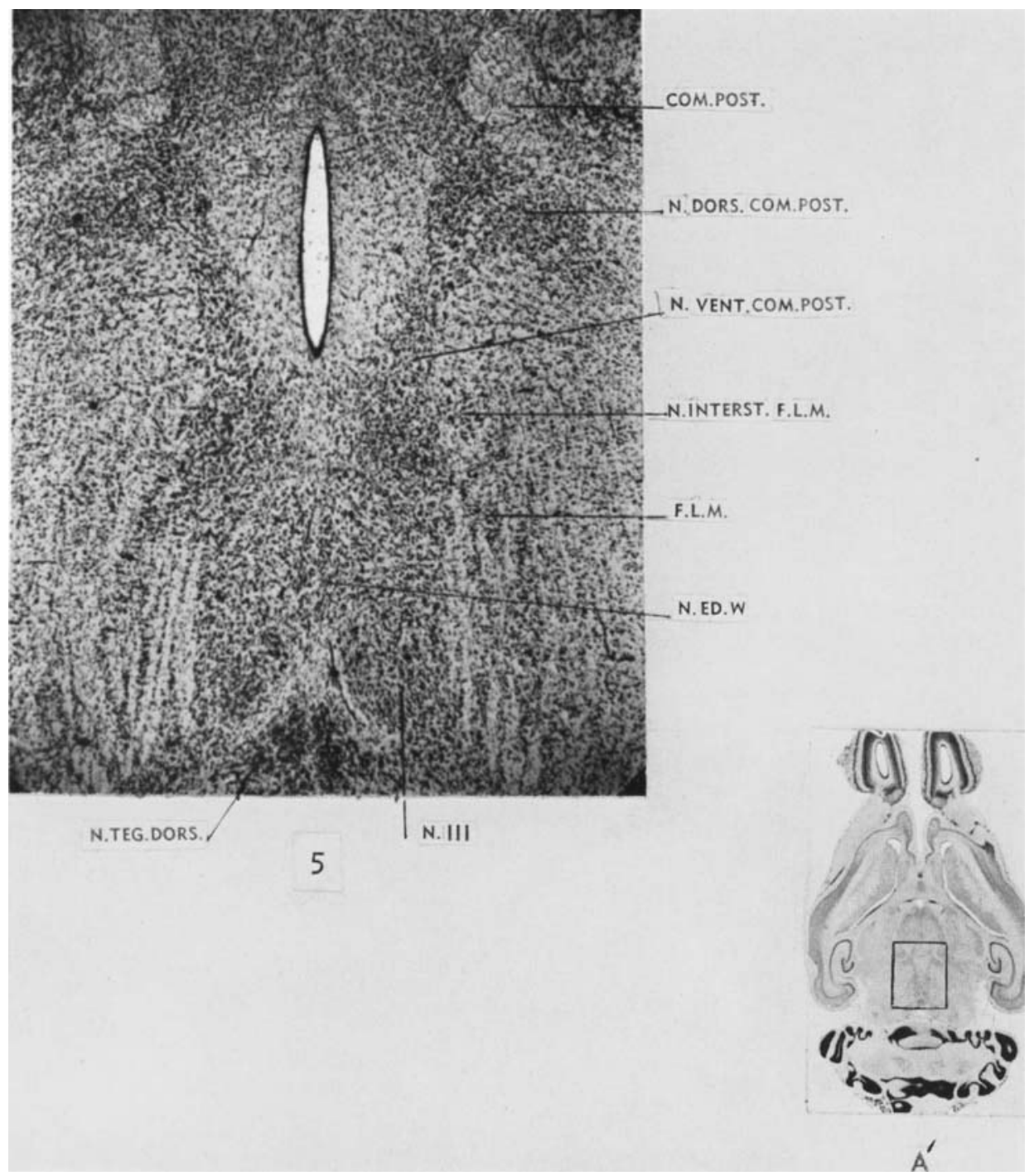


PJATE 4

\section{FXPLANATION OF FIGLRES}

6 Photomicrograph of a sagittal section through the brain of Didelphis virginiana jllustrating the relations of the habenulo-tectal and dorsal haberulotegmental tracts as they run ventrat to the posterior commissure. Note also the hypothalamic component of the dorsal longitudinal fasciculus swinging beneath the dorsal labenulo-tegmental traet in its eourse to the region of the dorsal tegmental uncleus. Weigert preparation. $\times 30$.

A'. Key plotomicrograph for figure $6 . \times 11$.

7 Ihotomicrograph of a transverse seetion through the series shown in figure 4 but rostral to the level of this latter figure. The photonierograph shows particularly the relations of certain tracts associated with the mammillary bodies. TR.MAM.THAL. designates the mammillo-thalamic and mammillo-tegmental system, the tegmental part of which predominates in this form, in which the greater number of so-called mammillo-thalamic fibers are associated with the supramammillary region. Weigert preparation. $\times 30$.

$B^{\prime}$. Key plotomierograpl for figure $7 . \times 3$. 
WUIZABETH I. THOMPSON

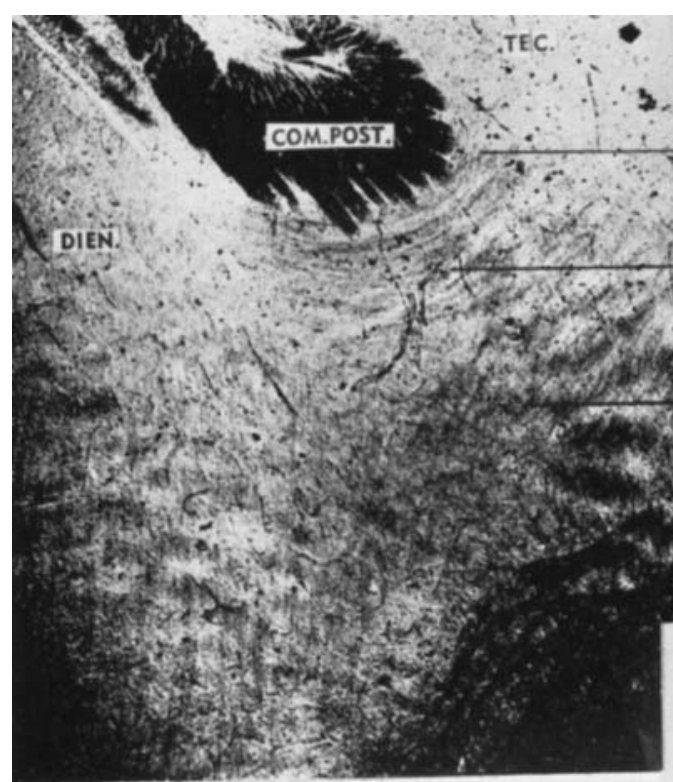

6

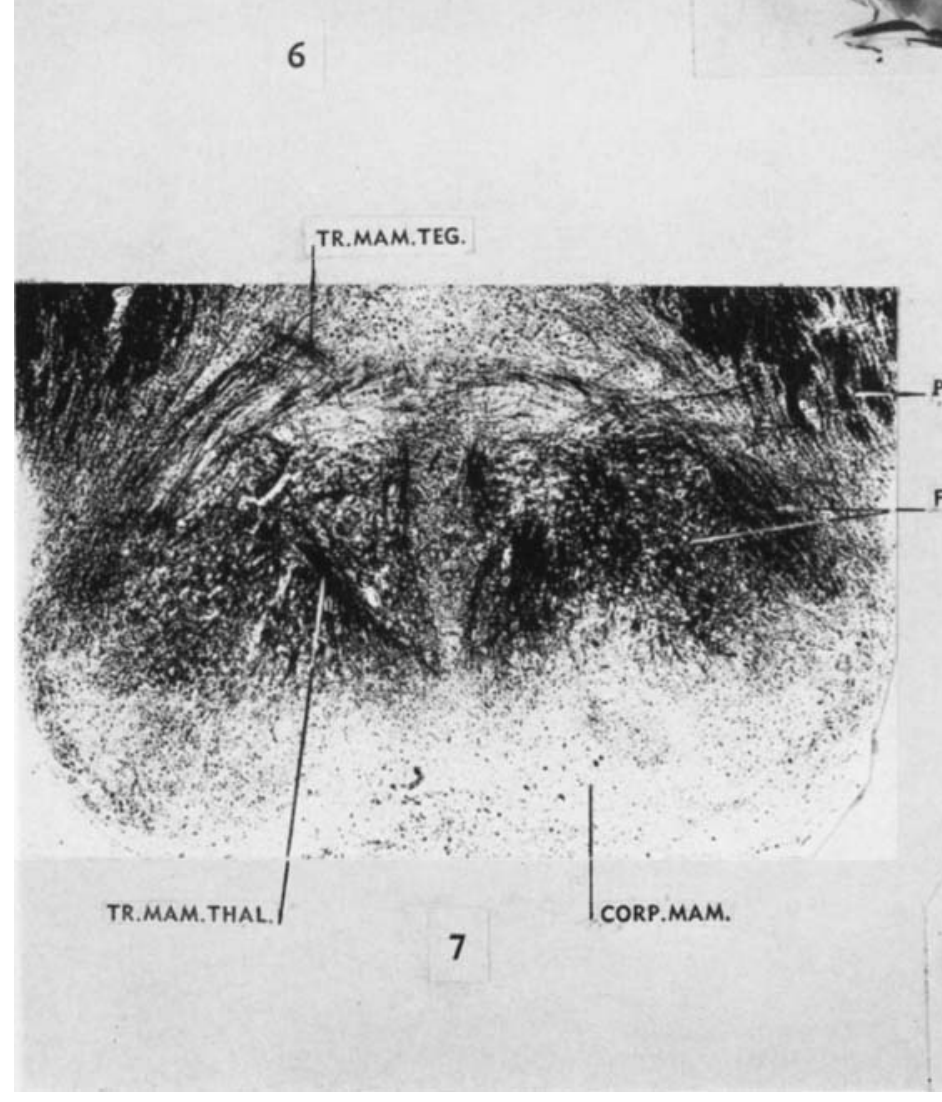

TR.HAB.TEC.

TR. HAB.TEG.DORS.

F.L.D.

TEG.

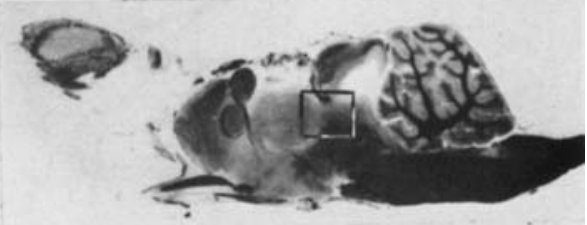

$A^{\prime}$

F.

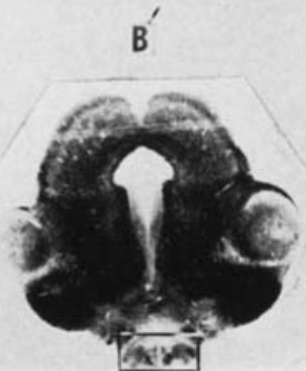


PLATLE כ

EXPLANATION OF FIGURES

8 Photomicrograph of a section of the brain of Didelphis rixginiana taken from the same series as figure 6 but very near the midplane. Note the position of the ventral habenulo-tegmental tract as it arches through the ficld dorsal to the interpeduncular melens. Weigert preparation. $\times 20$.

$\Lambda^{\prime}$. Key photomierograph for figuro $8 . \times 1 \frac{1}{3}$.

9 Photomicrograpl of a section slightly lateral to that shown in figure 8 . Attention is ealled particularly to the ventral mammillo-tegmental tract. $\times 30$. 13'. Key photomicrograph for figure 9 . $\times 11$. 


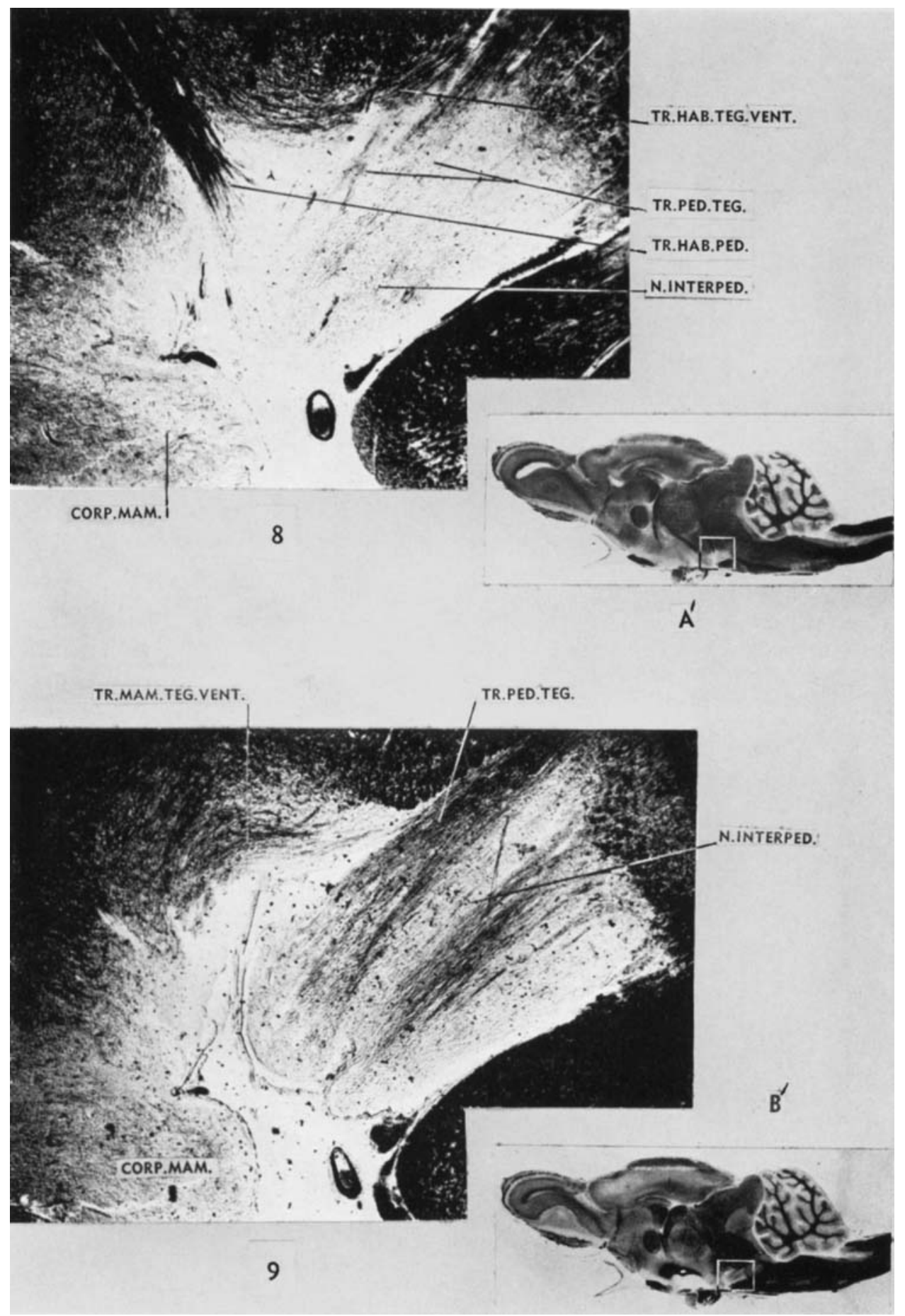




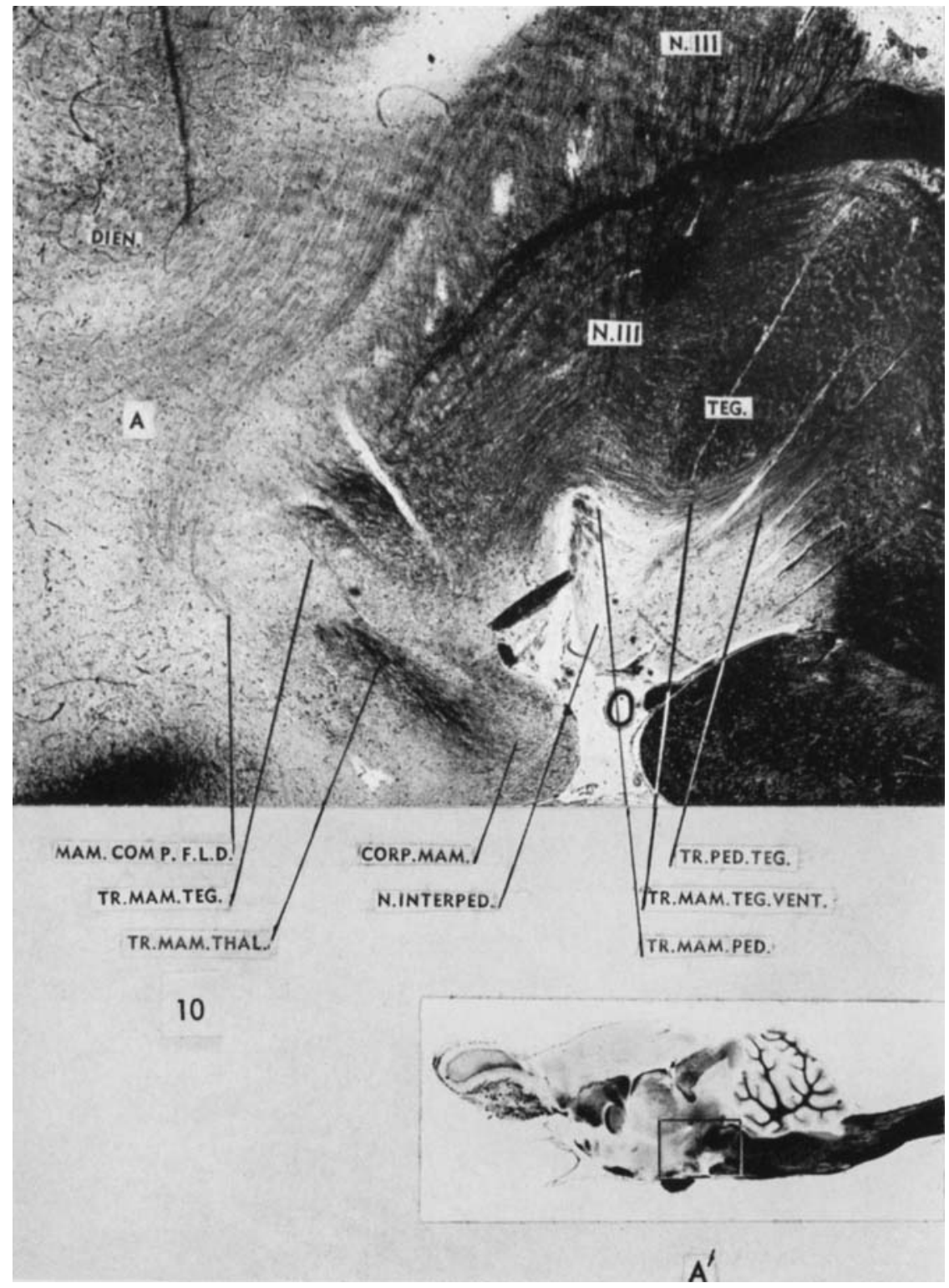

10 Photomicrograph of section from the same series used for figure 9. TR.MAM.THAL. designates the mammillo-thalamic and mammillo-tegmental system, the tegmental part of which predominates in this form, in which the greater number of so-called mammillo-thalamic fibers are assoeiated with the supramammillary region. Weigert preparation. $\times 20$.

A'. Key plotomicrograph for figure 10 . $\times 1 \stackrel{1}{ }$. 


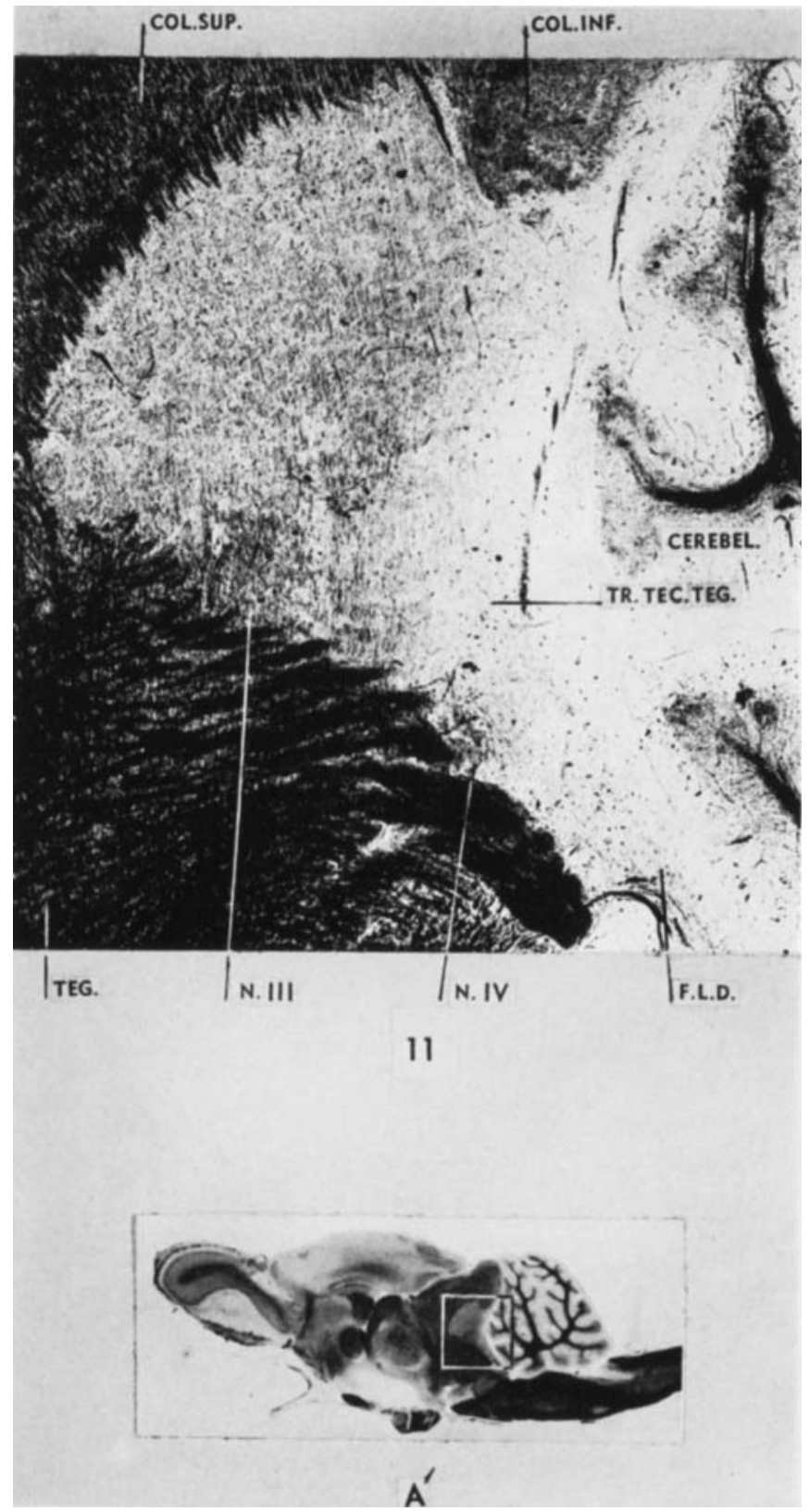

11 Photomierograph of a sagittal section immediately lateral to that illustrated in figure 9. It slows particularly the tecto-tegmental tract. Weigert preparation. $\times 20$.

A'. Key photomierograph for figure $11 . \times 14$. 


\section{PIATE 8}

\section{EXPLANATION OF FIGURES}

12 and 13 Two photomierographs taken from different regions of a single sagittal section directly medial to that illustrated in figure 10. Figure 12 shows the dorsal tegmental nucleus with the surrounding gray and fiber bundles. Figure 13 pietures the relations of the dorsal longitudinal fasciculus to the dorsal efferent nucleus. Note the fine fibers passing toward nucleus ambiguns. Weigert preparation. Figure 12 was taken at $\times 30$ and figure 13 at $\times 20$ magnification.

$A^{\prime}$ and $B^{\prime}$ indieate the positions of figures 12 and 13 respectively on the kery photomicrograph. $\times 1$. 


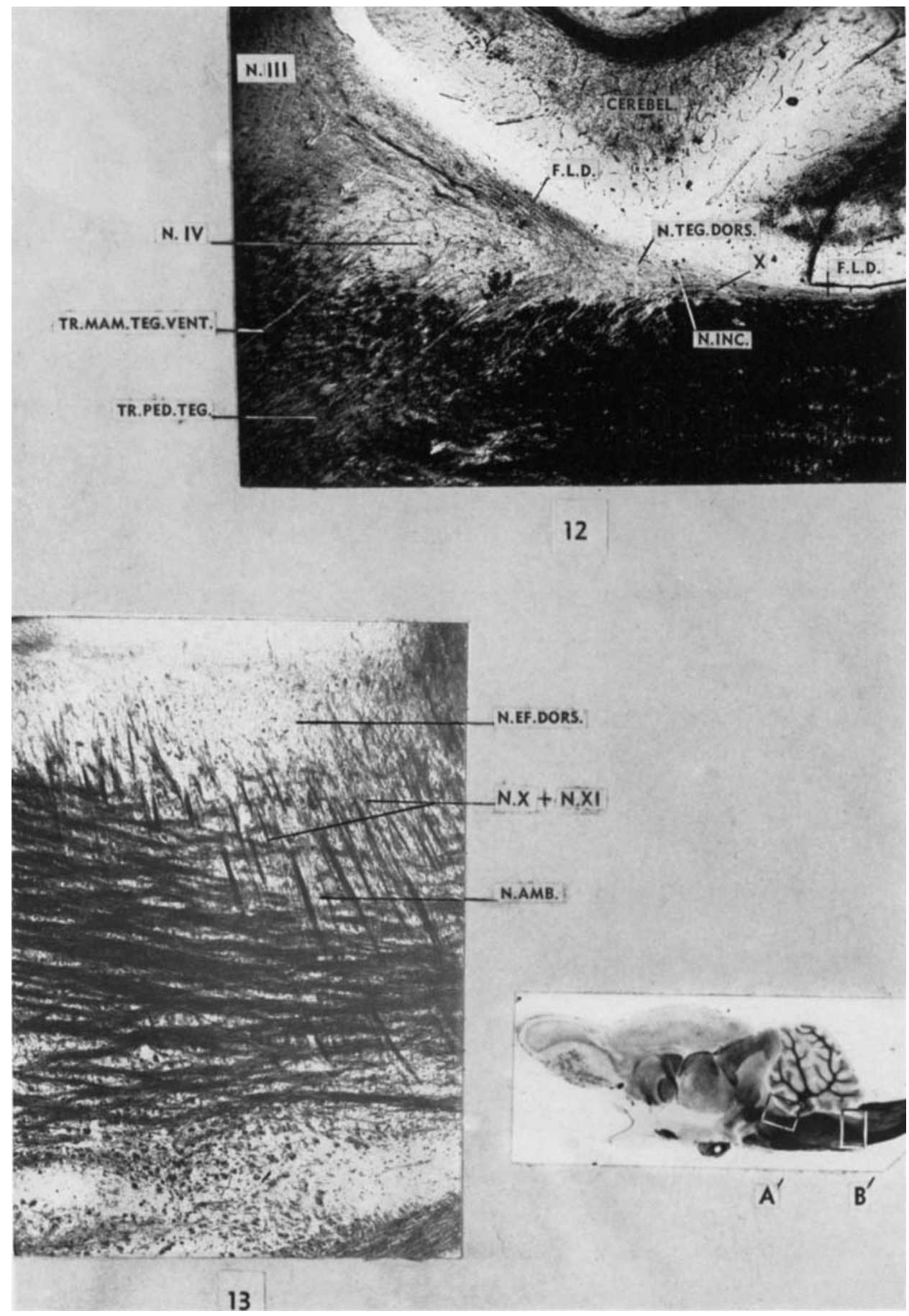




\section{PIAATE 9}

\section{EXPLANATION OF FIGURES}

14 Plotomicrograph of a transverse section through the medulla oblongata of Didelphis virginiana at the level at which the vagus and hypoglossal nuclei lie on the open floor of the ventricle. This ilhstrates certain fincr details of the connections of the dorsal longitudinal fasciculus (see text). Weigert preparation. $\times 30$.

$\mathrm{A}^{\prime}$. Key photomicrograph for figure $14 . \times 3$. 


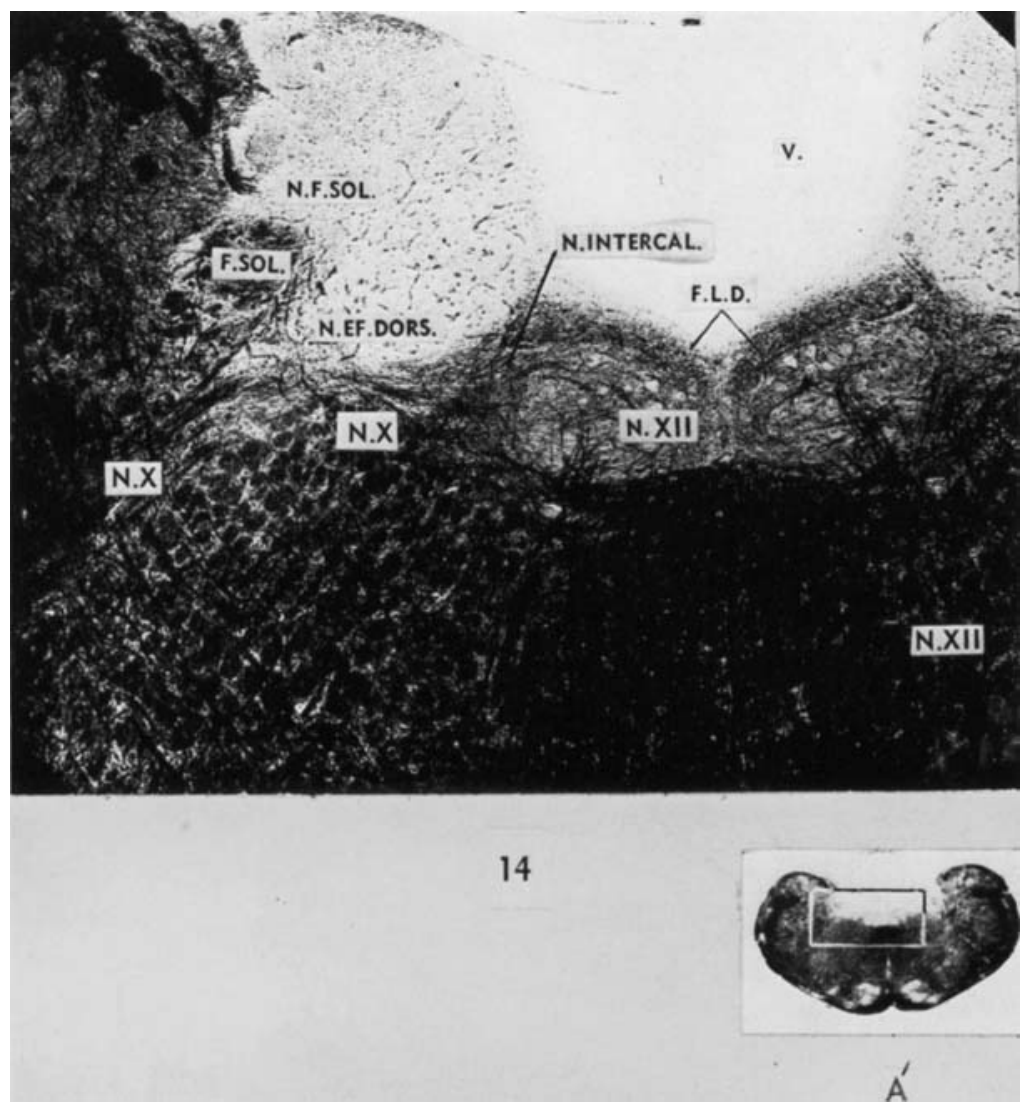


PLATE 10

EXPLANATION OF FIGURES

15 Plotomicrograph from the same sagittal section as that used in figure 10 but from a more caudal region. The figure illustrates particularly the relations of the dorsal longitudinal fasciculus as it overlies the hypoglossal nucleus. Weigert preparation. $\times 30$.

$\mathrm{A}^{\prime}$. Key photomicrograph for figure $15 . \times 1 \frac{1}{2}$.

16 Photomicrograph from a horizontal section of the brain of Didelphis virginiana. The picture illustrates the relations of the dorsal longitudinal fasciculus at caudal levels of the hypoglossal nucleus and its continuation behind this nueleus toward upper spinal cord levels. Weigert preparation. $\times 20$.

B'. Key photomicrograpls for figure $16 . \times 1 \frac{1}{1}$. 
DOLSA, I.ONGITUDINAJ, FASCICUJUS

FLIZABETH L. THOMPSON

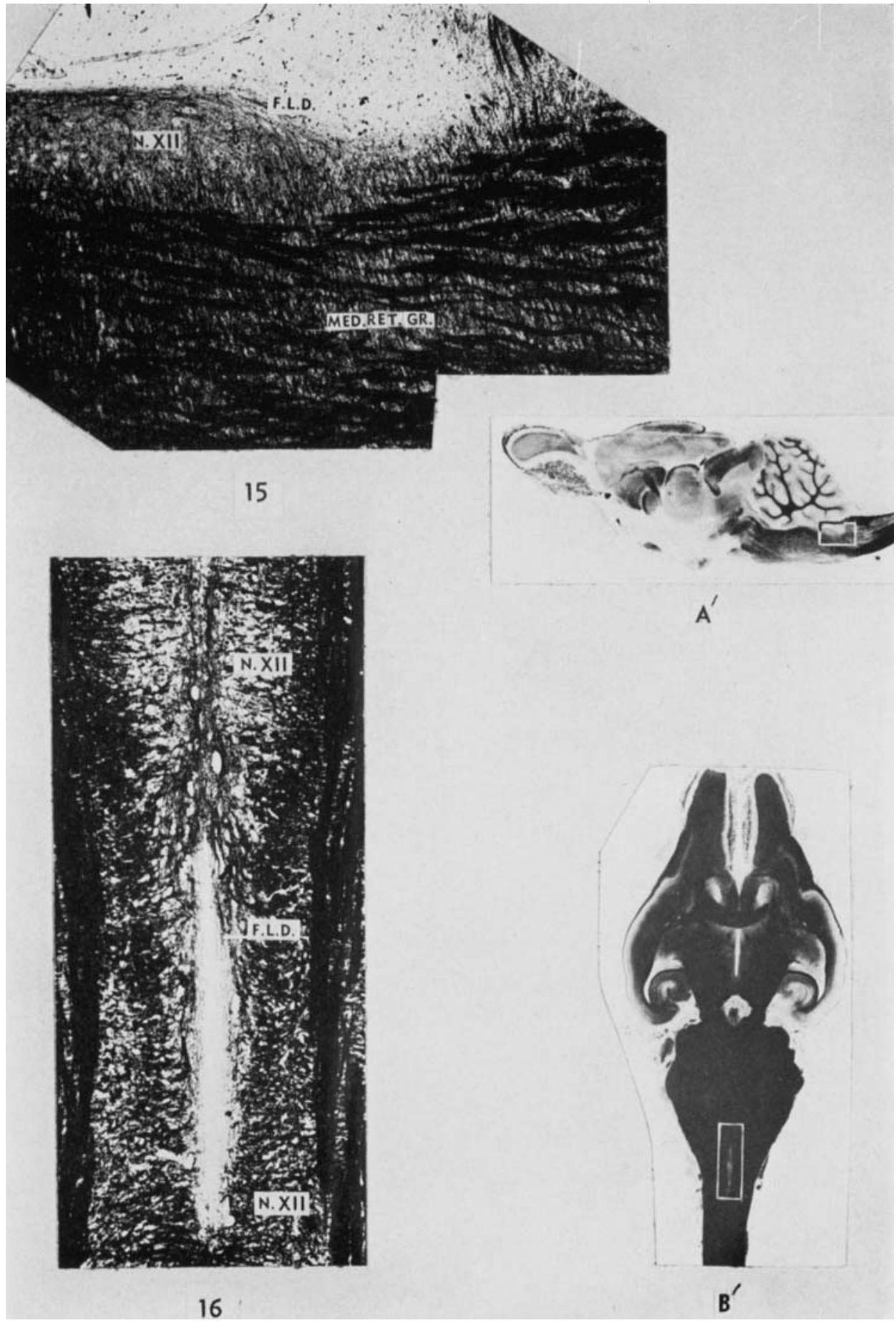

